\section{MS14-P14 The crystal structure of symplesite}

Gligor Jovanovski ${ }^{1}$, Tomče Runčevski ${ }^{2}$, Petre Makreski ${ }^{3}$, Robert E. Dinnebier ${ }^{2}$

1. Research Center for Environment and Materials, Macedonian Academy of Sciences and Arts, Bul. Krste Misirkov 2, 1000 Skopje, Macedonia

2. Max Planck Institute for Solid State Research, Heisenbergstrasse 1, 70569 Stuttgart, Germany

3. Institute of Chemistry, Faculty of Natural Sciences and Mathematics, Ss. Cyril and Methodius University, Arhimedova 5, 1000 Skopje, Macedonia

email: gligor@pmf.ukim.mk

Even after half a century of the discovery of the mineral symplesite there is no detailed report on its crystal structure. There is no deposited atomic coordinates and displacement parameters for symplesite in the ICSD and the only known crystallographic information is its unit cell symmetry and parameters. ${ }^{[1,2]}$ As a response on this lack of structural knowledge, we revisited the system and performed thorough crystallographic study on a natural sample from the Laubach Mine (Germany). Symplesite is a secondary mineral and often occurs with impurities. However, a careful selection of microcrystals provided a phase-pure sample. The crystal structure of symplesite was solved $a b$ initio from high-resolution, laboratory X-ray powder diffraction data and refined with the Rietveld method. The refinement of converged quickly giving unit cell parameters of $a=4.752(3) \AA, b=$ 7.786(5) $\mathrm{A}, c=9.260(6) \AA, \alpha=106.38(3)^{0}, \beta=93.05(4)^{0}$, $\gamma=98.14(4)^{0}$, and the symmetry was confirmed to be triclinic (with the space group $P-1$ ). It was shown that its crystal structure (Figure 1) is indeed isostructural to metavivianite. In this contribution, we present the crystal structure of symplesite, and we relate it to the crystal structures of the minerals metavivianite ${ }^{[3]}$ and parasymplesite. $^{[1,4]}$ In addition, we complemented the crystallographic study with infrared and Raman vibrational spectroscopy, ${ }^{[5]}$ drawing spectra-structure correlations.

\section{References}

[1] T. Ito, Acta Crystallogr. 7 (1954) 630c.

[2] K. Schmetzer, G. Tremmel, W. Bartelke, Neues Jahrb. Mineral., Abh. 138 (1980) 94-108.

[3] N.V. Chukanov, R. Scholz, S.M. Aksenov, R.K. Rastsvetaeva, I.V. Pekov, D.I. Belakovskiy, K. Krambrock, R.M. Paniago, A. Righi, R.F. Martins, F.M. Belotti, V. Bermanec, Mineral. Mag. 7683 (2012) 725-741.

[4] H. Mori, T. Ito, Acta Crystallogr. 3 (1950) 1-6.

[5] Makreski, S. Stefov, L. Pejov, G. Jovanovski, Spectrochim. Acta Part A 144 (2015) 155-162.

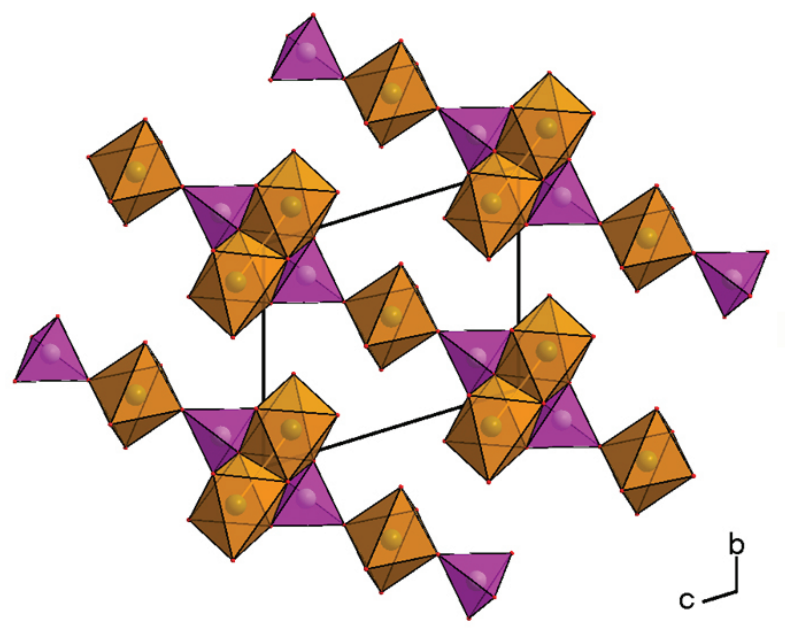

Figure 1. Crystal packing diagram of symplesite viewed perpendicular to the $a$-crystallographic axis.

Keywords: symplesite, mineral, crystal structure 